\title{
Reviving the Louisville Twin Study: An Introduction
}

\author{
Sally Ann Rhea ${ }^{1}$
}

Received: 13 October 2015 / Accepted: 16 October 2015/Published online: 26 October 2015

(C) Springer Science+Business Media New York 2015

\begin{abstract}
Researchers who are interested in breathing new life into the long dormant Louisville Twin Study (LTS) presented several papers at the 2015 meeting of the behavior genetics association. This brief introduction provides a short history of the Kentucky LTS as well as synopses of expanded analyses from the presentations on genetic change and continuity in cognitive and behavioral development and those exploring aspects of the influence of gene-environment interaction on cognition.
\end{abstract}

Keywords Louisville twin study - Twin research . Longitudinal study

In addition to publishing the abstracts from the 2015 meeting of the behavioral genetics association, most of the remainder of this volume is devoted to papers developed from one of the paper sessions-"Resuscitating the Louisville Twin Study: A Symposium in Honor of Adam P. Matheny." As a coordinator of another LTS-the Colorado Longitudinal Twin Study-I was heartened to learn that old twin studies never die, they just replicate and regenerate. The replication, of course, is that the Kentucky LTS provided the foundation for the proliferation of longitudinal twin studies around the world. And now we are witnessing the regeneration of the Kentucky LTS as researchers reanalyze the extant data, uncover buried treasures in the archives, and make the case for re-contacting and retesting participants as aging adults. Preliminary results were presented at the 2015 BGA meeting and expanded analyses are presented here.

Sally Ann Rhea

sally-ann.rhea@colorado.edu

1 University of Colorado-Boulder, Boulder, USA

\section{Short history of the Louisville Twin Study}

Although the introduction to the BGA symposium stated that the LTS was conducted across 30 years, the full span of the study took place across several more-nearly 45 years altogether. Beginning in 1957, Dr. Frank Falkner, a pediatrician at the University of Louisville Medical School, worked with hospitals to identify all multiple births in the Louisville area and receive placentas from those births (Vandenberg et al. 1968). Although many area hospitals were eager to help, this was a difficult process and engagement was inconsistent. Steven Vandenberg joined the study in 1960 and in March 1965 abandoned this daunting approach and initiated modern recruitmentidentification and contact through the county Department of Health. This method resulted in a greater number and broader socioeconomic range of participants. Blood typing was used to assign zygosity. Falkner and his first colleagues were primarily interested in physical development (Falkner 1959), but he welcomed the addition of other measures added by Vandenberg which led to multiple assessments of cognition, personality, physical development, and environmental context at multiple time points starting at age 3-months (Vandenberg et al. 1968).

In 1967 Vandenberg took a position at the University of Colorado and Ronald Wilson, who had joined the team in 1965 as the more standardized recruitment was getting underway, took the helm. Wilson oversaw the enrollment of more than 500 families and the assessment across a broad spectrum of measures of twins aged up to age 15 . Wilson was perhaps most well-known for his work on cognitive development, particularly drawing attention to patterns of "peaks and troughs over the ages" that nonetheless showed heritable synchronies in these patterns (Wilson 1983, p 302). He was, however, also interested in 
the other phenotypes studied in the LTS and published extensively with Matheny and other colleagues on longitudinal physical and behavioral measures.

Upon Wilson's untimely death in 1986, Adam Matheny, who had been the Associate Director for nearly 20 years, became the fourth Director of the Study. Although like his predecessors, Matheny published on a range of LTS measures, he may be recognized most for his contributions to our understanding of temperament and personality. His factor analyses of the infant behavior record (IBR) laid the groundwork for many genetic and longitudinal studies that used the assessment as their primary measure of infant and toddler behavior. Matheny retired from the university and the study in 2000 .

Due to a dearth of funding, longitudinal assessments were discontinued in the late 90s, although a special project recruiting infants lasted until 2002. Despite difficulties completing entry of collected data that resulted in a paucity of publications from the older ages, the LTS has an impressive publication record spanning six decades from Falkner's conceptual work (1957) to the infant-only data collection at the end (Riese et al. 2003).

\section{Contents of the special issue}

In the first paper, Finkel et al. use cognitive data from 8 assessments on 1032 individuals at ages 4-15 to replicate and extend Wilson's (1983) earlier findings regarding patterns of cognitive development. They apply biometric latent growth curve models to subscales of the age-appropriate Wechsler tests, the WPPSI and WISC-R, to examine differences in rates of growth along with genetic and environmental influences on that growth and evidence of continuity and discontinuity in cognitive development. As expected, they verify increasing heritability in younger children and plateaus as children reached the older ages. However, they also find independent genetic influence on change for some subscales, thus demonstrating that both continuity and innovation are at work.

Next, Davis et al. also explore genetic continuity and change but for a different phenotype-behavioral development. Previously, Matheny (1980, 1983) had analyzed LTS IBR data at ages 3-24 months. This expanded analysis of the three factors identified by Matheny (1980), taskorientation, affect-extraversion, and activity, includes nearly twice as many subjects and additional time-points, 30 and 36 months. Employing Cholesky decomposition and comparing multiple models, the authors find varying patterns of correlations for the differing scales indicating new genetic variation for task orientation at 6,9 , and 12 months; shared environment influencing stability for affect-extraversion through 12 months and genetic factors for stability beginning at 18 months; and both genetic and environmental influences contributing to change in activity scores.

Thus, again, the authors find evidence for both continuity and change.

Beam et al. take the use of new techniques for old data even further with a complex analysis of the full-scale IQ scores across ages $4-15$. They apply a reciprocal effects modeling approach to the analysis of longitudinal cognitive data. They test whether models that allow for developmentally plausible effects of phenotypes on subsequent individual twin environments, e.g., niche-picking, can provide a better fit to full-scale IQ scores between ages 4 and 15 than a basic simplex model. Their results support a view that the combined and increasing effects of genetic and environmental influences shape individuals' environments.

The final paper continues the theme of investigating the interaction of environment and heritability on IQ. Turkheimer et al. examine these data in the context of the Scarr-Rowe hypothesis which posits that for cognitive ability the influence of shared environment increases and genetic influence decreases in adverse environments. Employing structural equation models to analyze the interaction of Hollingshead socioeconomic (SES) scores and age 7 WISC IQ, they find some support for replication of earlier findings that demonstrate the Scarr-Rowe interaction occurs for Performance and Full Scale IQ but not for Verbal IQ.

\section{Conclusion}

Kay Phillips, one of the first researchers of the other LTS in Colorado, became the accidental final director of the Kentucky LTS. She was delighted to join Matheny as a data analyst in 1988 but was surprised to find herself the Acting Director when he retired 12 years later. Phillips ushered in the collection of DNA samples and contemporary genomic work, but funding constraints prevented her from completing that project. It is inspiring to think that the authors of the papers in this special issue may soon resuscitate the Louisville Twin Study and honor the legacy of Faulkner, Vandenberg, Wilson, Matheny and Phillips by recovering unanalyzed data and securing funding to conduct new assessments with the more than 500 families who participated as long as 50 years ago.

\section{References}

Falkner F (1957) An appraisal of the potential contribution of longitudinal twin studies. In: Nature $\mathrm{T}$ (ed) The nature and 
transmission of the genetic and cultural characteristics of human populations. Milbank Memorial Fund, Philadelphia

Falkner F (1959) Skeletal maturation: an appraisal of concept and method. Am J Phys Anthropol 16:381-396

Matheny AP Jr (1980) Bayley's infant behavior record: behavioral components and twin analyses. Child Dev 51:1157-1167

Matheny AP Jr (1983) A longitudinal twin study of stability of components from Bayley's infant behavior record. Child Dev $54: 356$
Riese ML, Swift HM, Barnes SL (2003) Newborn twin outcome predicted by maternal variables: differentiation by term and sex. Twin Research 6:12-18

Vandenberg SG, Stafford RE, Brown AM (1968) The Louisville Twin Study. In: Vandenberg SG (ed) Progress in human behavior genetics. Johns Hopkins Press, Baltimore, pp 153-204

Wilson RS (1983) The Louisville twin study: developmental synchronies in behavior. Child Dev 54:298-316 